\title{
SUBFOSSIL CHIRONOMIDS FROM 18 LAKES IN SOUTHERN AND NORTHERN FINLAND
}

Tomi P. Luoto

\author{
Department of Geology, P.O. Box 64, FIN-00014 University of Helsinki, Finland, \\ E-mail:tomi.luoto@helsinki.fi
}

\section{Introduction}

Midge and especially chironomid (Diptera: Chironomidae) larvae provide an excellent data source of environmental conditions in aquatic ecosystems, particularly in lakes and ponds, where they live abundantly in the bottom of littoral and pelagic zones. Chironomids are a very diverse midge family, for example Paasivirta (2007) lists over 750 species in Finland. Some species are ecologically sensitive, living only in certain types of waters. Their chitinous head capsules preserve in lake sediments as subfossil remains and have been used to interpret past environmental changes in lakes, e.g. changes in temperature, water depth, salinity, productivity, hypolimnetic oxygen and $\mathrm{pH}$ (Walker 2001). Subfossil chironomid analysis has also been used in contemporary ecological studies, as the chironomid assemblage in the topmost sediment layer, if not disturbed, is considered to represent the present chironomid fauna and sampling of the surface sediment is fairly easy and effective. The major disadvantage in subfossil chironomid analysis is the difficulty in identification, because it is often impossible to identify to species or even genus level. However, for example Olander et al. (1999), Larocque et al. (2001) and Nyman et al. (2005) have gathered important information on distribution of chironomids in northern Fennoscandia based on surface sediment samples. Although these studies have led to highly developed chironomid-based palaeotemperature inference models, they are restricted to subarctic regions and do not cover the southern areas of Fennoscandia.
The aim of the present study is to provide data on the distribution of chironomids in southern and northern Finland and to examine whether faunal patterns in distribution exist between these regions. Therefore, 18 lakes in Finland, 11 situated in the southernmost part of the state and 7 in the northernmost part, were studied for their subfossil chironomid fauna. This study presents preliminary results from a wider investigation of chironomid distribution in Finland.

\section{The study area}

The 18 lakes were chosen to represent different lake types in southern $\left(60^{\circ} 13^{\prime}\right.$ to $\left.60^{\circ} 26^{\prime} \mathrm{N}\right)$ and northern Finland $\left(69^{\circ} 40^{\prime}\right.$ to $69^{\circ} 53^{\prime} \mathrm{N}$ ) (Figure 1). Catchment vegetation of the lakes spans from boreal coniferous forests in the south to tundra vegetation in north. The mean annual air temperature varies between 4.5 (south, HelsinkiVantaa airport) and $-2.0^{\circ} \mathrm{C}$ (north, Kevo research station), and the mean annual precipitation from $649 \mathrm{~mm}$ to $395 \mathrm{~mm}$, respectively. The altitude of the lakes varies from 15 to $404 \mathrm{~m}$ a.s.l. and altitude corrected mean July air temperatures were calculated for individual lakes (Laaksonen 1976) (Table 1). The range in mean July air temperature varies from 16.8 in south to $11.0{ }^{\circ} \mathrm{C}$ in north. All northern lakes were oligotrophic and their surface areas varied from ca. 20 to 90 ha., whereas southern lakes varied more in their trophic status and were generally smaller (Table 1). 


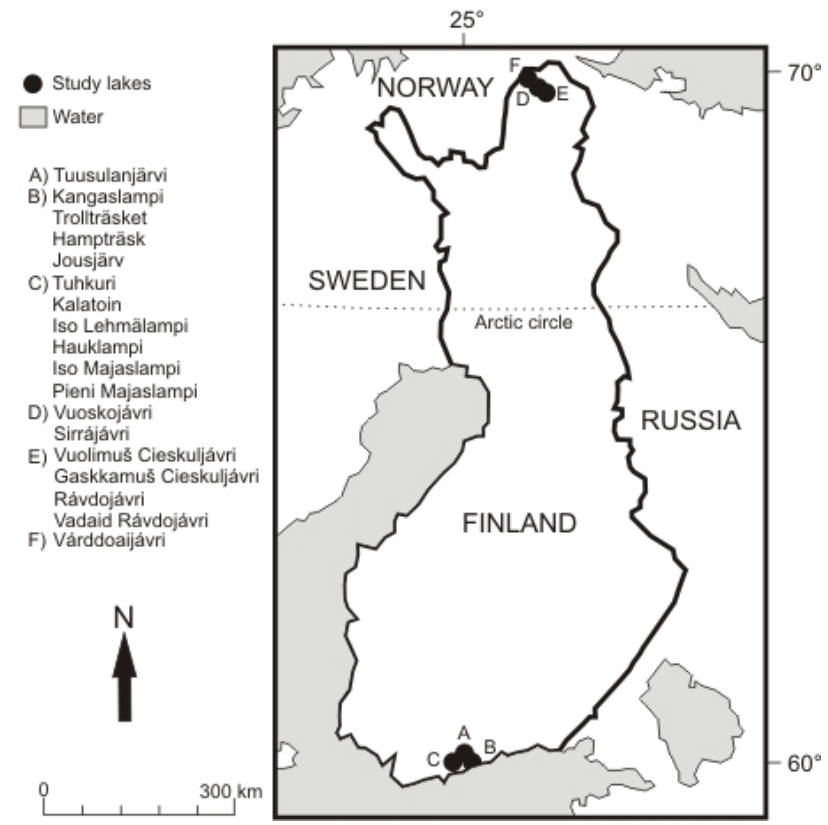

Figure 2. Location of the study sites. Lakes A-C are located in boreal forests, lakes D-E in mountain birch woodland and $\mathrm{F}$ in subarctic tundra.

Table 1. Location, climate and other characteristics of the examined lakes.

\begin{tabular}{lccccccc}
\hline Lake & $\begin{array}{c}\text { Latitude } \\
\left({ }^{\circ}\right)\end{array}$ & $\begin{array}{c}\text { Longitude } \\
\left({ }^{(} \mathrm{E}\right)\end{array}$ & $\begin{array}{c}\text { Altitude } \\
(\mathrm{m} \text { a.s.l. })\end{array}$ & $\begin{array}{c}\text { MeanTJul } \\
\left({ }^{\circ} \mathrm{C}\right)\end{array}$ & $\begin{array}{c}\text { Area } \\
(\text { ha) }\end{array}$ & $\begin{array}{c}\text { Trophic } \\
\text { status }\end{array}$ & $\begin{array}{c}\text { Vegetation } \\
\text { zones* }\end{array}$ \\
\hline Varddoaijavri & 69.53 & 26.31 & 404.0 & 11.01 & 28.5 & oligotrophic & Ba \\
Vadaid Ravdojavri & 69.40 & 27.13 & 301.0 & 11.59 & 92.2 & oligotrophic & MBW \\
Gaskkamus Cieskuljavri & 69.43 & 27.07 & 282.6 & 11.70 & 15.0 & oligotrophic & MBW \\
Ravdojavri & 69.40 & 27.12 & 275.8 & 11.74 & 62.3 & oligotrophic & MBW \\
Vuolimus Cieskuljavri & 69.44 & 27.05 & 269.4 & 11.77 & 45.7 & oligotrophic & MBW \\
Sirrajavri & 69.45 & 26.53 & 208.0 & 12.12 & 18.2 & oligotrophic & MBW \\
Vuoskojavri & 69.44 & 26.56 & 145.0 & 12.48 & 19.2 & oligotrophic & MBW \\
Pieni Majaslampi & 60.19 & 24.35 & 97.3 & 16.35 & 1.1 & oligotrophic & SPB \\
Iso Majaslampi & 60.19 & 24.35 & 92.7 & 16.37 & 6.3 & oligotrophic & SPB \\
Iso Lehmälampi & 60.20 & 24.36 & 91.7 & 16.38 & 5.1 & oligotrophic & SPB \\
Kalatoin & 60.20 & 24.37 & 89.5 & 16.39 & 0.9 & dystrophic & SPB \\
Hauklampi & 60.18 & 24.36 & 75.7 & 16.47 & 2.7 & oligotrophic & SPB \\
Tuhkuri & 60.20 & 24.38 & 73.7 & 16.48 & 13.7 & oligotrophic & SPB \\
Jousjärv & 60.20 & 25.11 & 37.3 & 16.69 & 0.5 & dystrophic & SPB \\
Tuusulanjärvi & 60.26 & 25.03 & 37.8 & 16.69 & 600.0 & eutrophic & SPB \\
Trollträsket & 60.20 & 25.09 & 24.0 & 16.77 & 1.3 & mesotophic & SPB \\
Hampträsk & 60.17 & 25.15 & 20.3 & 16.79 & 3.8 & mesotophic & SPB \\
Kangaslampi & 60.13 & 25.08 & 14.6 & 16.82 & 1.4 & eutrophic & SPB \\
\hline
\end{tabular}

$* \mathrm{Ba}=$ barren tundra, $\mathrm{MBW}=$ mountain birch woodland, $\mathrm{SPB}=$ spruce, pine and birch forest. 


\section{Materials and methods}

The surface sediment samples were obtained with a Limnos gravity corer between February and April in 2005. The sediment samples for subfossil chironomid analysis were prepared using standard methods described in Hofmann (1986) and Walker (2001). A minimum of 100 chironomid head capsules were identified from each sample. The identification was based mainly on Wiederholm (1983). Heiri et al. (2004) was used to identify the Tanytarsini, Sæther $(1975,1976)$ and Walker et al. (1992) for some of the Orthocladiinae and Rieradevall \& Brooks (2001) for the Tanypodinae larvae. The WWW Field Guide to subfossil Midges (Walker 2007) was also very helpful. The nomenclature follows the above mentioned literature.

Detrended correspondence analysis (DCA) was performed using the program CANOCO, version 4.52 (ter Braak 2003) to explore patterns in the distribution of the chironomid taxa in Finland. The DCA was run with detrending by segments, square-root-transformation of species abundances and down weighting of rare species. DCA is an indirect ordination method that summarizes the variation of the species assemblages along the DCA axes.

\section{Results and discussion}

From the sediments of the 18 lakes, a total of 2310 chironomid head capsules were counted and identified to genus or species level. In all, 66 taxa were identified; 40 Chironominae (23 Chironomini, 16 Tanytarsini, 1 Pseudochironomini), 22 Orthocladiinae, 3 Tanypodinae and 1 Diamesinae. The most common chironomid taxa (Figure 2, Table 2) were Tanytarsus undif. (mean abundance in the lakes $7.8 \%$ ) and Psectrocladius sordidellus type (7.7\%). Ablabesmyia monilis type (6.8\%), Monopsectrocladius calcaratus type $(6.4 \%)$ and Procladius (6.3\%) were also common. Monopsectrocladius calcaratus type, Ablabesmyia monilis type, Dicrotendipes pulsus type, Tanytarsus undif. and Procladius occurred in 17 lakes (Table 2) while none of the taxa occurred in all lakes. The most evenly distributed taxa in the lakes, with high effective number of occurrences (Hill's N2), were Ablabesmyia monilis type (13.1), Dicrotendipes pulsus type (11.7) and Psectrocladius sordidellus type (11.0) (Table 2).

Table 2. Chironomid occurrences, Hill's N2 diversity index, maximum and mean percentages and calculated optimum temperatures based on the 18 study lakes.

\begin{tabular}{lccccc}
\hline & Occurrences & Hill's N2 & Maximum & Mean & Opt. temp. $\left({ }^{\circ} \mathrm{C}\right)$ \\
\hline Micropsectra radialis type & 1 & 1.0 & 4.1 & 0.2 & 11.01 \\
Hydrobaenus pilipes type & 2 & 2.0 & 0.7 & 0.1 & 11.37 \\
Heterotrissocladius brundini type & 6 & 3.6 & 10.8 & 1.4 & 11.42 \\
Tanytarsus lugens type & 10 & 7.2 & 10.1 & 2.5 & 11.6 \\
Thienemannimyia & 5 & 4.6 & 1.4 & 0.2 & 11.68 \\
Sergentia coracina type & 7 & 5.9 & 8.4 & 2.0 & 11.69 \\
Zalutschia tatrica type & 4 & 3.0 & 3.5 & 0.4 & 11.75 \\
Heterotrissocladius grimshawi type & 5 & 4.0 & 5.2 & 1.0 & 11.90 \\
Parakiefferiella nigra & 2 & 1.5 & 2.6 & 0.2 & 11.90 \\
Cricotopus pulchripes type & 6 & 4.9 & 4.7 & 1.0 & 11.93 \\
Micropsectra insignilobus type & 9 & 4.2 & 19.8 & 3.2 & 11.97 \\
Protanypus & 1 & 1.0 & 2.6 & 0.1 & 12.12 \\
Corynocera ambigua & 7 & 4.0 & 15.4 & 2.3 & 12.29 \\
Stempellinella & 1 & 1.0 & 0.7 & 0.0 & 12.48 \\
Cricotopus (I.) sp. & 4 & 2.5 & 5.0 & 0.5 & 12.53
\end{tabular}




\begin{tabular}{|c|c|c|c|c|c|}
\hline & Occurrences & Hill's N2 & Maximum & Mean & Opt. temp. $\left({ }^{\circ} \mathrm{C}\right)$ \\
\hline Constempellina brevicosta & 5 & 2.3 & 5.1 & 0.5 & 12.85 \\
\hline Paratanytarsus austriacus type & 2 & 1.4 & 3.6 & 0.2 & 13.14 \\
\hline Paratanytarsus undif. & 14 & 8.7 & 16.2 & 4.1 & 13.25 \\
\hline Micropsectra bidentata type & 7 & 4.0 & 4.3 & 0.5 & 13.52 \\
\hline Monopsectrocladius calcaratus type & 13 & 6.2 & 36.8 & 6.4 & 13.55 \\
\hline Microtendipes pedellus type & 13 & 7.9 & 7.9 & 2.2 & 13.68 \\
\hline Paratanytarsus penicillatus type & 8 & 6.5 & 5.0 & 1.2 & 13.81 \\
\hline Cricotopus (I.) sylvestris type & 15 & 9.6 & 5.8 & 1.4 & 14.06 \\
\hline Pagastiella orophila & 8 & 6.0 & 2.7 & 0.5 & 14.13 \\
\hline Heterotrissocladius marcidus type & 6 & 3.8 & 6.8 & 0.9 & 14.14 \\
\hline Paracladopelma & 2 & 2.0 & 0.9 & 0.1 & 14.31 \\
\hline Cricotopus undif. & 10 & 7.7 & 5.4 & 1.3 & 14.46 \\
\hline Psectrocladius sordidellus type & 17 & 11.0 & 26.0 & 7.7 & 14.71 \\
\hline Cladotanytarsus mancus type & 9 & 4.3 & 11.3 & 1.5 & 14.77 \\
\hline Phaenopsectra flavipes type & 7 & 6.2 & 1.9 & 0.5 & 14.87 \\
\hline Zalutschia zalutschicola & 10 & 7.9 & 6.0 & 1.9 & 14.87 \\
\hline Ablabesmyia monilis type & 17 & 13.1 & 15.6 & 6.8 & 14.95 \\
\hline Dicrotendipes pulsus type & 17 & 11.7 & 12.1 & 3.9 & 14.96 \\
\hline Heterotanytarsus apicalis type & 6 & 3.7 & 9.9 & 1.6 & 15.22 \\
\hline Psectrocladius (Mesopsectrocladius) & 4 & 2.9 & 2.6 & 0.3 & 15.27 \\
\hline Cryptochironomus & 2 & 1.8 & 1.6 & 0.1 & 15.37 \\
\hline Polypedilum nubeculosum type & 12 & 9.5 & 3.1 & 1.0 & 15.63 \\
\hline Tanytarsus undif. & 17 & 7.4 & 41.9 & 7.8 & 15.64 \\
\hline Procladius & 17 & 6.4 & 38.6 & 6.3 & 15.67 \\
\hline Psectrocladius (Allopsectrocladius) & 12 & 4.3 & 25.0 & 3.5 & 15.74 \\
\hline Cladopelma viridulum type & 13 & 6.5 & 7.7 & 1.3 & 15.91 \\
\hline Pseudochironomus prasinatus type & 5 & 4.2 & 2.9 & 0.5 & 16.06 \\
\hline Tanytarsus pallidicornis type & 13 & 7.3 & 12.4 & 3.0 & 16.07 \\
\hline Tanytarsus chinyensis type & 6 & 2.7 & 7.3 & 0.7 & 16.31 \\
\hline Chironomus anthracinus type & 11 & 6.5 & 13.6 & 2.9 & 16.31 \\
\hline Limnophyes & 6 & 3.6 & 8.7 & 1.3 & 16.34 \\
\hline Paratendipes albimanus type & 1 & 1.0 & 5.8 & 0.3 & 16.39 \\
\hline Corynoneura lobata type & 5 & 1.6 & 29.7 & 2.1 & 16.39 \\
\hline Chironomus plumosus type & 11 & 3.9 & 19.7 & 2.5 & 16.41 \\
\hline Lauterborniella agrayloides type & 5 & 4.6 & 2.3 & 0.4 & 16.54 \\
\hline Corynoneura scutellata type & 5 & 3.0 & 5.8 & 0.6 & 16.56 \\
\hline Nanocladius ( $N$.) rectinervis type & 4 & 3.0 & 3.0 & 0.4 & 16.56 \\
\hline
\end{tabular}




\begin{tabular}{lccccc}
\hline & Occurrences & Hill's N2 & Maximum & Mean & Opt. temp. $\left({ }^{\circ} \mathrm{C}\right)$ \\
\hline Tanytarsus mendax type & 7 & 6.4 & 6.8 & 1.8 & 16.57 \\
Microchironomus tener type & 1 & 1.0 & 11.0 & 0.6 & 16.69 \\
Endochironomus impar type & 2 & 1.9 & 1.6 & 0.1 & 16.69 \\
Endochironomus albipennis type & 3 & 2.4 & 3.4 & 0.4 & 16.74 \\
Orthocladius sp. & 3 & 2.7 & 4.0 & 0.5 & 16.75 \\
Einfeldia pagana type & 3 & 2.5 & 6.8 & 0.7 & 16.75 \\
Rheotanytarsus & 5 & 3.6 & 4.3 & 0.6 & 16.76 \\
Polypedilum sordens type & 3 & 1.9 & 3.4 & 0.3 & 16.76 \\
Mesocricotopus thienemannii & 1 & 1.0 & 1.5 & 0.1 & 16.79 \\
Glyptotendipes pallens type & 4 & 2.3 & 10.3 & 0.9 & 16.79 \\
Omisus caledonicus & 1 & 1.0 & 0.9 & 0.0 & 16.82 \\
Parachironomus varus type & 1 & 1.0 & 3.4 & 0.2 & 16.82 \\
Endochironomus tendens type & 1 & 1.0 & 0.9 & 0.0 & 16.82 \\
Kiefferulus tendipediformis type & 1 & 1.0 & 1.7 & 0.1 & 16.82 \\
\hline
\end{tabular}

Several chironomid taxa occurred mainly in the northern lakes, whereas many were found only from southern sites (Figure 2). Some taxa, e.g. Psectrocladius sordidellus type and Ablabesmyia monilis type were found abundantly in both northern and southern lakes (Figure 2). Micropsectra radialis type occurred only in Várddoaijávri (Figure 2, Table 2), which is the coldest of the lakes, located in the subarctic tundra of the northernmost Finland. Also Heterotrissocladius brundini type and Paratanytarsus undif., were at their highest abundance in Várddoaijávri. Paratanytarsus undif. occurred also in all mountain birch woodland lakes and in some boreal forest lakes. A clear northern distribution with preference to mountain birch woodland lakes (Table 1), was observed for Tanytarsus lugens type, Thienemannimyia, Sergentia coracina type, Zalutschia tatrica type, Heterotrissocladius grimshawi type, Parakiefferiella nigra, Cricotopus pulchripes type, Micropsectra insignilobus type, Protanypus, Corynocera ambigua, Cricotopus (I.) sp., Constempellina brevicosta and Paratanytarsus austriacus type. A southern distribution was observed for many taxa (Figure 2). Polypedilum sordens type, Rheotanytarsus, Orthocladius sp., Endochironomus impar type, Tanytarsus mendax type, Nanocladius (N.) rectinervis type, Corynoneura scutellata type, Lauterborniella agrayloides type, Corynoneura lobata type, Paratendipes albimanus type, Limnophyes, Tanytarsus chinyensis type, T. pallidicornis type, Pseudochironomus prasinatus type, Cladopelma viridulum type and Psectrocladius (Allopsectrocladius) occurred mainly in southern lakes, which are situated in the boreal forest vegetation zone. Glyptotendipes pallens type, Einfeldia pagana type, Endochironomus albipennis type, Microchironomus tener type and Chironomus plumosus type also had southern occurrences, and they showed further preference for nutrient rich lakes (Figure 2, Table 1). Also Chironomus anthracinus type and Procladius had their maximum abundances in southern, nutrientrich lakes. The general results of the distribution of chironomids in the present study seem to agree with other studies (e.g. Brodersen and Quinlan 2006; Brooks 2006). 

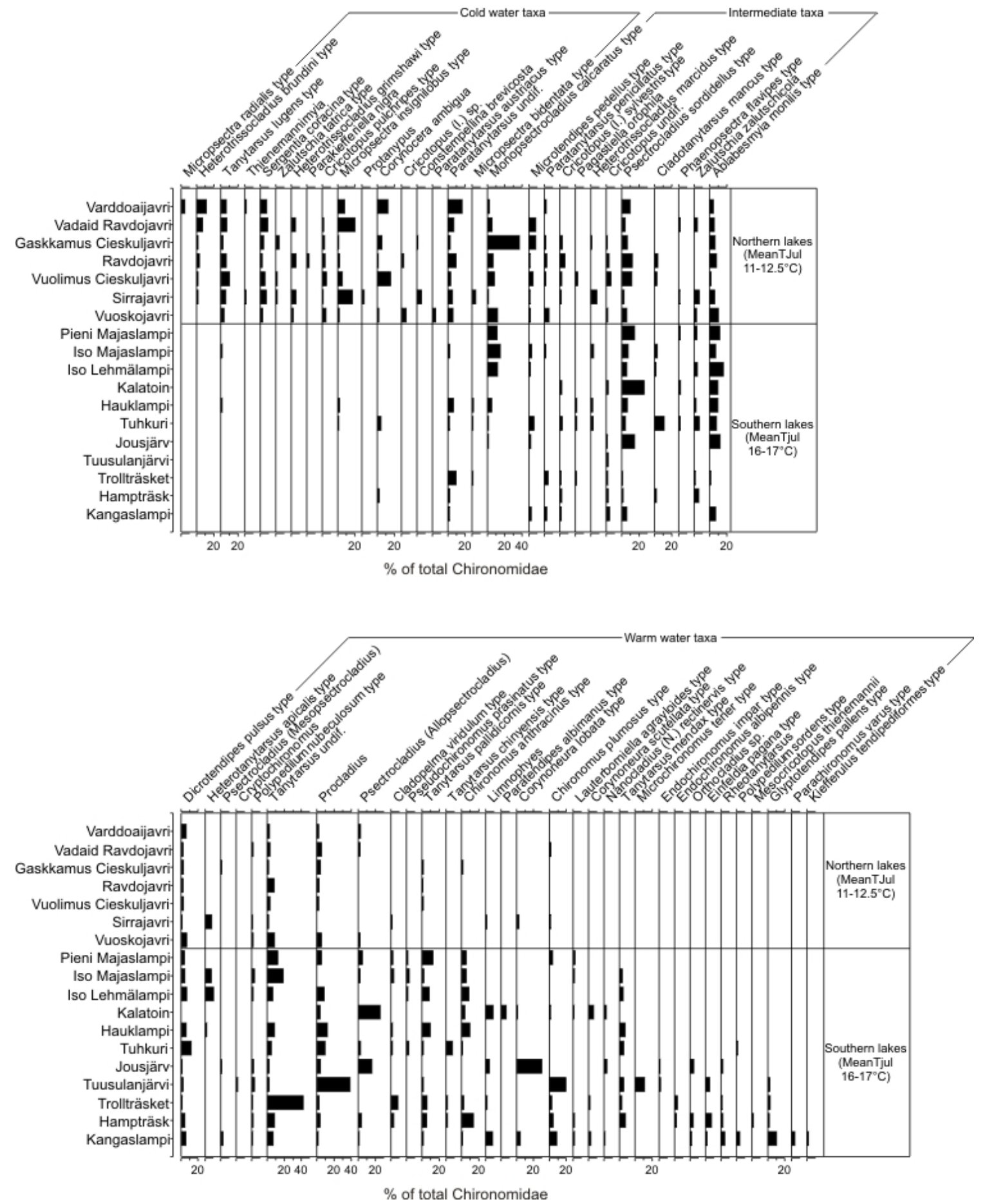

Figure 3. Distribution of the most common Chironomidae. The taxa are ordered based on their optimum temperatures from the coldest (left) to the warmest (right) and the lakes are ordered based on their mean July air temperatures from the coldest (top) to the warmest (bottom).

The DCA ordination diagram (Figure 3) indicates that the samples (i.e. lakes) are clearly clustered into several groups according to their chironomid fauna. The scores for the southern and northern lakes are distinctly different from each other; the southern lakes having low or intermediate values for DCA axis 1 and northern lakes having high values. The northern lakes had very similar scores along both DCA axes suggesting that their chironomid assemblages were very similar. There was also clustering among the southern lakes. The meso-eutrophic southern lakes had rather low 
values along both DCA axis and the most eutrophic lake (Tuusulanjärvi) had distinctly low values for both axes. The dystrophic, macrophyterich lakes had highest scores for the DCA axis 2 values and low axis 1 values and the oligotrophic southern lakes had scores in the center of the ordination diagram.

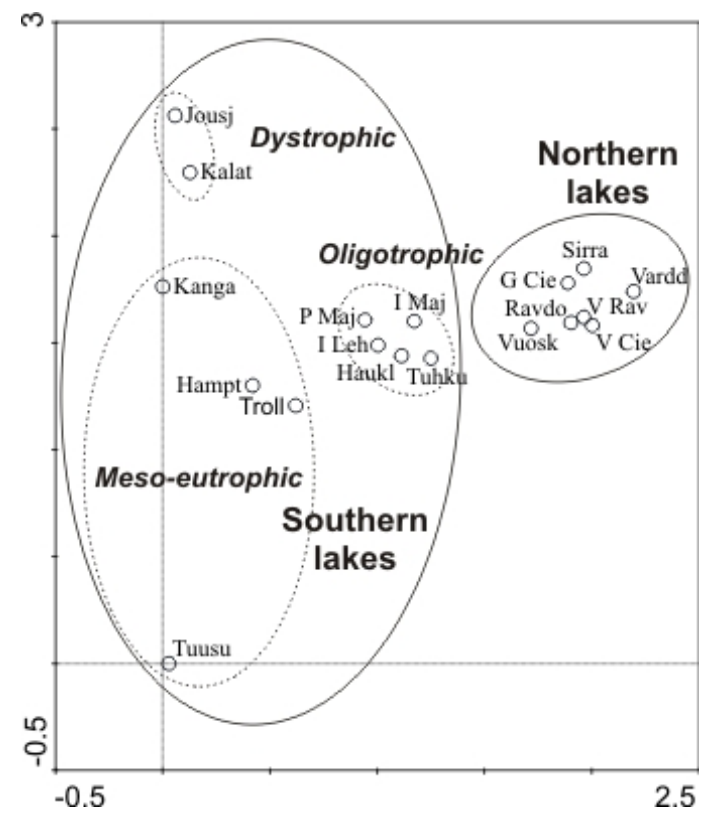

Figure 4. Figure 3. DCA plot for samples based on the chironomid assemblages in the 18 lakes.

According to the current results, it appears that the occurrences of some chironomid taxa are restricted to either southern or northern lakes and some were found in both regions (Figure 2). This suggests that faunal patterns exist in distribution of chironomids in Finland. It is possible that climatic factors are behind this geographical distribution of chironomids, since climate differs considerably between southern and northern Finland (Table 1) and temperature is known to affect the occurrence of chironomids (Brooks 2006). Because such differences in distribution were found, optimum temperatures, based on lake specific July air temperatures (meanTJul) were calculated for each taxon (Table 2) and the chironomids were grouped to cold, intermediate and warm water inhabitants (Figure 2). However, it is likely that many other chemical, physical or ecological factors besides climate affect their distribution and are influencing these faunal patterns. For example the northern lakes in the present study were much larger than the southern ones and this may be one contributing factor causing the differences in northern and southern chironomid assemblages. Olander et al. (1999) found the organic content of the sediment (measured as loss on ignition: LOI) and lake water temperature to be the key factors and Nyman et al. (2005) showed that LOI, total organic carbon (TOC), $\mathrm{pH}$ and lake specific July air temperature were the most significant factors affecting chironomid distributions in western Finnish Lapland. Larocque et al. (2001) concluded that mean July air temperature, LOI and maximum lake depth were the most important environmental variables in subarctic northern Sweden. The present study provided data only on chironomids in southern and northern lakes and therefore presents no information on distribution in the geographical region in between. For more detailed information on distribution patterns of chironomids more research is needed from a wider spatial range.

\section{Conclusions}

The southern lakes were generally dissimilar in their chironomid assemblages compared to northern lakes, and furthermore showed some clear faunal patterns. Chironomid assemblages were similar within the 5 oligotrophic lakes, 2 dystrophic lakes and 4 meso-eutrophic lakes (Figure 3). It is probable that the limnological diversity in lake ecosystems in southern Finland, e.g. variation in the trophic status, water color and macrophyte-cover, provided suitable habitats for different chironomid taxa, resulting in different faunal assemblages in certain types of lakes and that similar conditions does not exist in northern Finland.

\section{Acknowledgements}

This study was funded by the Finnish Entomological Society, the Nordenskiöld Foundation, the Walter and Lisi Wahl's fund, the Finnish Graduate School in Geology and the Ephippium project (The Academy of Finland, grant no. 1107062). Liisa Nevalainen, Seija Kultti, Susanna Kihlman and the Kevo research station staff are appreciated for the assistance with the field work. Liisa Nevalainen is also thanked for her comments on the manuscript and Kati Ojanen for her remarks on the text. Valuable comments of an anonymous reviewer are acknowledged. 


\section{References}

Brodersen, K. P. and Quinlan, R. 2006. Midges as palaeoindicators of lake productivity, eutrophication and hypolimnetic oxygen. Quatern. Sci. Rev. 25: 1995-2012.

Brooks, S. J. 2006. Fossil midges (Diptera chironomidae) as palaeoclimatic indicators for the Eurasian region. Quatern. Sci. Rev. 25: 1894-1910.

Heiri, O., Ekrem, T. and Willassen, E. 2004. Larval head capsules of European Micropsectra, Paratanytarsus and Tanytarsus (Diptera: Chironomidae: Tanytarsini). (http://www.bio.uu.nl/ palaeo/Chironomids/T anytarsini/intro.htm).

Hofmann, W. 1986. Chironomid analysis. In: Berglund B.E. (eds) Handbook of Holocene Palaeoecology and Palaeohydrology. John Wiley \& Sons, New York, pp 715-727.

Laaksonen, K. 1976. The dependence of mean air temperatures upon latitude and altitude in Fennoscandia (1921-1950). - Ann. Acad. Sci. Fenn. 119A: 5-19.

Larocque, I., Hall, R. I. and Grahn, E. 2001. Chironomids as indicators of climate change: a 100-lake training set from a subarctic region of northern Sweden (Lapland). - J. Paleolimnol. 26: 307-322.

Nyman, M., Korhola, A. and Brooks, S. J. 2005. The distribution and diversity of Chironomidae (Insecta: Diptera) in western Finnish Lapland, with special emphasis on shallow lakes. - Global Ecol. Biogeogr. 14: 137-153.

Olander, H., Birks, H. J. B., Korhola, A. and Blom, T. 1999. An expanded calibration model for inferring lakewater and air temperatures from fossil chironomid assemblages in northern Fennoscandia. The Holocene 9: 279-294.
Paasivirta, L. 2007. Chironomidae (Diptera: Nematocera) in the biogeographical provinces of Finland.

(http://www.saunalahti.fi/jailmon/FinnishChir onomidae.htm).

Rieradevall, M. and Brooks, S. J. 2001. An identification guide to subfossil Tanypodinae larvae (Insecta: Diptera: Chironomidae) based on cephalic setation. - J. Paleolimnol. 25: 8199.

Sæther, O. A. 1975. Nearctic and Palearctic Heterotrissocladius (Diptera: Chironomidae). - Bull. Fish. Res. Bd Can. 193: 1-67.

Sæther, O. A. 1976. Revision of Hydrobaenus, Trissocladius, Zalutschia, Paratrissocladius, and some related genera (Diptera: Chironomidae). - Bull. Fish. Res. Bd Can. 195: 1-287.

ter Braak, C. J. F. 2003. Program CANOCO, Version 4.52. Biometris - quantitative methods in the life and earth sciences. Plant Research International, Wageningen University and Research Centre, Wageningen, The Netherlands.

Walker, I. R., Oliver, D. R. and Dillon, M. E. 1992. The larva and habitat of Parakiefferiella nigra Brundin (Diptera: Chironomidae). Netherlands Journal of Aquatic Ecology 26: 527-531.

Walker, I. R. 2001. Midges: Chironomidae and related Diptera. In: Smol, J. P., Birks, H. J. B. and Last WM (eds) Tracking Environmental Change Using Lake Sediments. Volume 4: Zoological Indicators. Kluwer Academic Publishers, Dordrecht, The Netherlands, pp 43-66.

Walker, I. R. 2007. The WWW Field Guide to Fossil Midges.

(http://www.paleolab.ca/wwwguide/).

Wiederholm, T. (ed.) 1983. Chironomidae of the Holarctic region. Keys and diagnoses. Part 1 Larvae. - sEnt. Scand. Suppl. 19, 457 pp. 